\title{
17 Internet-telephone consultation service for older persons
}

\author{
Stawomir Tobis, Katarzyna Wieczorowska-Tobis \\ and Agnieszka Neumann-Podczaska
}

The COVID-19 pandemic provoked implementations of novel services incorporating innovative technological and organisational solutions. In the available literature, there were no interdisciplinary approaches which would combine the students of various medical specialties with the expertise of their academic teachers and address the medical and functional needs of older individuals during the pandemic. Our project allowed older individuals to be helped at home with a broad range of issues, which has not been described before in the literature and practice description.

\section{Introduction}

The outbreak of the COVID-19 pandemic caused the introduction of unprecedented limitations in the functioning of society. Restrictions introduced concerned the operation of many institutions but also related to interpersonal contacts. The recommendation to stay at home led, among other things, to reduce the accessibility of health care facilities (e.g., GP and specialist clinics). In Poland, due to the transformation of some hospitals into COVID-19 units, in which only patients with a positive SARS-CoV-2 result are treated, entire teams of specialist clinics operating at these hospitals, from one day to another, ceased to be available to the general public (Pinaks et al. 2020: e924730). In this situation, many older people had no one to turn to when it came to doubts and questions related to drugs, but also everyday functioning.

Moreover, significant restrictions in the functioning of other health care units, resulting from staff limitations and complicated procedures, caused diminished availability of medical consultations. Reports of problems with accessing medical advice are confirmed in many countries. At the same time, it is noted that the reduction in the number of consultations results not only from limited availability but also from the patients' reservations and hence the fear of seeking necessary help. 
Among the factors of increased risk of developing COVID-19, and also those of a severe course of the disease, older age and selected chronic diseases (heart diseases, diabetes, cancer - at present or in the previous three years, and chronic obstructive pulmonary disease - COPD - or severe asthma) are pointed out (Gemes et al. 2020: 401; Neumann-Podczaska et al. 2020: 988). Since age is a risk factor for all these diseases in older persons, it is they who were mainly ordered to remain at home when the pandemic started. This fact is particularly important combined with data showing that frailty, one of the most typical morbidity traits in geriatrics, was one of the essential mortality factors in COVID-19 patients (Hägg et al. 2020). Henceforth, various institutions, including nursing homes, developed targeted strategies (Wrona et al. 2020: e451).

All institutions involved in the activation of older adults were also closed overnight; older adult centres, day centres for older adults and the senior clubs have ceased to function. What's more, the message to the older adults by all involved in activation activities and the media has changed dramatically - also overnight. Previously, much attention was paid to increasing the activity of older persons and their social involvement. They were educated that - in order to function well, stay fit for a long time and live in their own home - they have to leave the house, meet people and be active, both physically and cognitively (Delle Fave et al. 2018: 828; Langhammer et al. 2018: 7856823). Meanwhile, due to the pandemic, they were suddenly supposed to stay at home. Unsurprisingly, the older adults began to ask how to reconcile these restrictions with activity and exercise, which created a sudden increase in the demand for online services, but also for all actions that might be taken to improve the everyday functioning.

Particular attention should be paid to the older people taking into consideration the stress related to uncertainty about the future and the lack of a sense of security resulting from suddenly finding themselves in new circumstances. One of the typical features of the ageing process is less flexibility and a more difficult adaptation to new situations (Van Bookel et al. 2017: 11). Undoubtedly, the pandemic created not only a sense of threat, but also forced a rapid implementation of new solutions - mostly remote, and thus allowing for social distancing and reducing the risk of exposure to the novel coronavirus; there was practically no time to get to know and get used to them.

On the other hand, the forms of classes and courses for students were changed from one day to another. Those whose future work is based on direct contact with the patient/client were deprived of the possibility of interacting with their future caretakers. This is all the more important as contemporary healthcare, and social care paradigms place the person at the centre - the approach known as person-centred care (The American Geriatrics Society 2016: 15). Building a valuable therapeutic relationship between the professional and the patient or client is an essential part of this 
approach. It seemed impossible to simulate this in a remote learning setting. Hence, the search for solutions that could be used in this context began.

\section{Internet-telephone consultation service for older persons: how it works}

Information about the service and its operation was published in the press and television, both local and nationwide. Internet news websites and the website of the Poznań City Hall were also involved in disseminating the info. Additionally, information was spreading by word of mouth, as the older persons themselves informed each other about the possibilities of consultation.

The principle of the service's operation is presented in Figure 17.1.

Older people called the advertised phone number. The information given clearly stated that within it CS, students consulted under the supervision of academic teachers, i.e., that each recommendation issued was discussed with them.

The first contact with the older person was made by the student responsible for the technical aspects of the connection; they set the day and time of consultation and found out what were the older adult's preferences regarding the connection. Video chat via Messenger (Facebook) or WhatsApp was preferred, but telephone contact was also possible. Older people were informed that - if they do not use a communicator yet - once they decide in favour of a video contact, they would receive help from students in installing and launching the appropriate application.

After settling the details, the negotiated calls followed. Each consultation consisted of at least two connections. During the first one, an interview was performed. Before the main part of the conversation, a short recording regarding the protection of personal data and their processing in connection with the General Data Protection Regulation (GDPR) was played. After

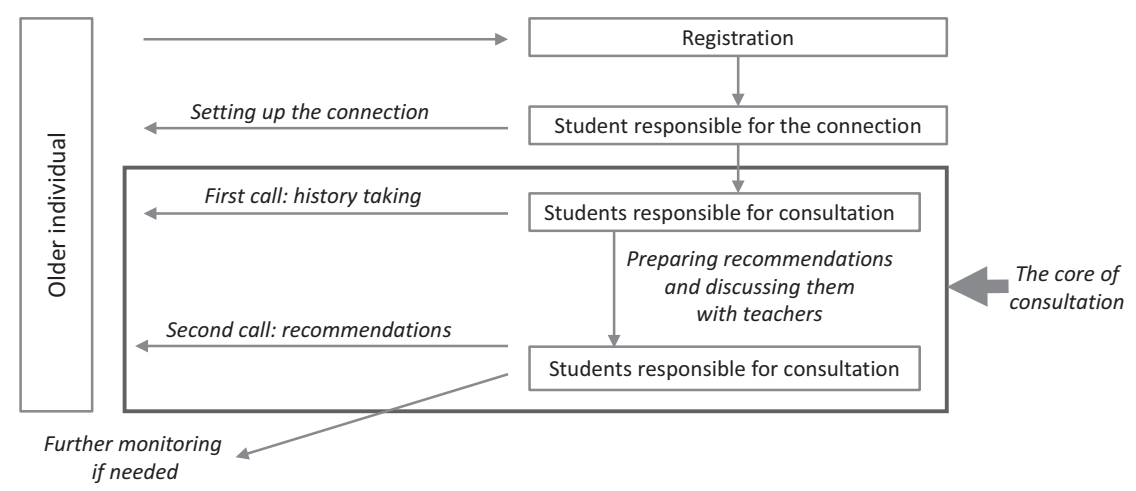

Figure 17.1 The Internet-Telephone Consultation Service (itCS) 
obtaining the older adult's consent to the processing of personal data for consultation purposes, the students collected an interview, which varied depending on the consultation path. During this interview, older adults also raised their doubts or problems with which they turned to the itCS. After collecting the interview, the students made an appointment for a second consultation within a few days.

In the meantime, the students prepared answers to the questions asked by the older adults, solved the reported problems and developed individual recommendations for all patients. The prepared recommendations were discussed with academic teachers.

The second call involved issuing recommendations to the older adults. If necessary, monitoring rules for recommended solutions were also established. Therefore, the dates of further connections were often set to check whether the recommendations brought the desired effect. An additional intervention modifying the originally issued recommendations was also possible.

The students operating the itCS were volunteers. They acted on the basis of the Volunteer Agreement (including also the detailed Regulations for the operation of itCS, which constituted an appendix to the Agreement) concluded between the clinical unit, being an integral organisational part of the Poznan University of Medical Sciences, and the student. This agreement regulated the principles of voluntary activity and secured the students against possible claims of patients related to the consultations received. Two types of the consultation were provided:

- Drug consultations, in which the students of the Faculty of Medicine and Faculty of Pharmacy participated. The purpose of these consultations was to answer questions about the principles of drug use, how to take specific medications (e.g. before or after eating), what to do when, for example, a drug is about to end, or can additional over-the-counter medicines or dietary supplements be added to the treatment? An interview was done about the drugs to which the questions were asked, but also about the laboratory results and hospital discharge cards to ensure that the advice was best possible. A large proportion of the reported problems concerned older adults' doubts about the use of certain groups of preparations. In such a case, the role of the volunteers was to provide comprehensive information on indications for the use of these drugs, including the balance of benefits and complications that may result from applying a given therapy. Volunteers often managed to convince the older patients to start using again medications prescribed by a doctor, often significantly improving the prognosis in a given condition, but having, every now and then, an unjustifiably bad reputation.

- Consultations regarding the occupational status and level of activity provided by students of occupational therapy, with the aim to find and indicate possible activities for older people confined to the own four walls 
and to improve (or at least maintain) their physical and mental fitness and well-being. They were also supposed to meet neither with friends nor with members of their families. All this presented a reversion of the narrative from "go out and be active" to "stay at home and isolate." The consequence was that that the developed solutions and established habits were no more applicable and many of the older adults were at risk of not only declining fitness but also mental problems. The students thus performed thorough interviews to define the occupational status of the older subject in as broad a way as possible, taking into account various physical and social factors. For every client, recommendations addressing their unique needs, requirements, and preferences were elaborated, discussed with academic teachers, and presented to the older person. The solutions proposed ranged from physical exercise adapted to the living space of the client, via cognitive stimulation, to gaming and other pleasing activities.

The academic teachers participating in the consultations were - depending on the path - a pharmacist with a special background in geriatrics and a medical doctor (geriatric specialist) or teachers involved in educating the students of occupational therapy, with preparation in geriatrics (e.g., completed postgraduate studies in gerontology and geriatrics).

\section{Discussion of the project's results}

To assess the results of the project and to understand the perspective of older adults on the undertaken activities, in-depth interviews with older adults were carried out using communicators commonly used for consultations in the itCS. Examples of the characteristics of people who participated in the interviews are presented in Table 17.1.

During the interviews, older adults particularly emphasised the possibility of establishing contact with young people. Occasionally, setting up the connection took longer than the consultation itself, but this process was perceived as a valuable, unique lesson in intergenerational interactions. Whenever a video call was possible, the older adults appreciated the possibility of a visual contact with the consulting students and clearly gained an additional sense of security. Moreover, for those who were able to set up their visual communicator for the first time, it was like opening a new window to the world, because they could also use it in other contexts later on. The first connection attempts were assisted by students who provided the necessary technological support; this was particularly important in the light of a study by Peek et al. who showed that external support could play an important role in this respect, not only for the willingness to use the technology at the moment but also for the stability of the use of technological devices in the future (Peek et al. 2019: 236).

The process of setting up a connection can be viewed as a kind of intergenerational workshop, during which students learned how to communicate 
Table 17.1 Examples of characteristics of people who benefited from consultations

\begin{tabular}{|c|c|}
\hline Characteristics of the consulted person & $\begin{array}{l}\text { Type of consultation } \\
\text { provided }\end{array}$ \\
\hline $\begin{array}{l}\text { A man, } 81 \text { years old, lives with his wife, heard about the } \\
\text { itCS on TV, very active before the pandemic, among } \\
\text { others, involved in educational activities for older adults. } \\
\text { Interested in herbal medicine; during the pandemic, he } \\
\text { began using a large number of dietary supplements to } \\
\text { increase his immunity. }\end{array}$ & Drug consultation \\
\hline $\begin{array}{l}\text { A woman, } 70 \text { years old, lives alone, occasional contacts with } \\
\text { her family; she found her way to the itCS thanks to friends. } \\
\text { She could not cope with the excess of free time during } \\
\text { the lockout; active before the pandemic participated in } \\
\text { numerous activities organised for older adults. }\end{array}$ & $\begin{array}{l}\text { Consultation } \\
\text { regarding the } \\
\text { occupational } \\
\text { status and level } \\
\text { of activity }\end{array}$ \\
\hline $\begin{array}{l}\text { A } 67 \text {-year-old woman, single, found the itCS thanks to } \\
\text { information on TV; unable to cope with the excess of free } \\
\text { time during the lockout; was active before the pandemic, } \\
\text { participated in a wide range of activities for older adults. }\end{array}$ & $\begin{array}{l}\text { Consultation } \\
\text { regarding drugs, } \\
\text { occupational } \\
\text { status and level } \\
\text { of activity }\end{array}$ \\
\hline
\end{tabular}

with the older subjects. In practice, they learned in particular that when you are blazing a trail in an unknown world, and you need to teach someone something new, one of the essential rules is to adjust the pace of the instructions given to the recipient's perception capability. They also learned to cope with frustration, both for themselves and for the patient, if the connection setup was complicated and took a long time to complete. Such training is an important lesson for the young generation, perfectly skilled in technology, as it confronts a different perspective in which what is obvious for them is not obvious for another person; it appears complex, often terrifyingly alien, and also unattainable. Therefore, such experience teaches empathy, which is necessary for future work with another person. One of the students who helped to establish the connection said

first of all, it was an invaluable opportunity for me to gain experience in contact with the patient (...). I learned how to talk, how and what questions to ask to get the information I needed. I learned that everyone should be approached individually, not treated as "just another patient." I was very positively surprised by how open the patients were. I had the idea that younger patients were open-minded rather than older. Meanwhile, itCS has completely changed my opinion about older adults. Previously, I was afraid of contact with an older patient, and now I recall this experience in superlatives.

This statement shows, on the one hand, the fear of a young person from contact with an older patient, and on the other hand, the positive experience of this contact. According to many available studies, education through 
direct contact with older subjects has a positive effect on students' attitudes towards old age (Adelman et al. 2007: 1445; Brikenmaier et al. 2009: 784). Among the potential benefits of such contact, the reduction of the phenomenon of "ageism" is particularly emphasised, as well as greater readiness of young people to undertake activities in the field of gerontology in the future (Cottle \& Glover 2007: 501; Ferguson 2012: 713).

For the students, participation in the project was also an opportunity to gain experience of working in a team, including seeking solutions based on brainstorming. The diversity of problems which older adults reported to the itCS caused that students learned how to deal with various life situations. All this is of special importance, because due to the epidemiological situation, both in Poland and abroad, practical classes where students had daily contact with older persons, were suspended. The itCS activities are in line with the paradigm of education through practice, the need of which has been emphasised for many years, particularly in the area of social work, resulting in not only a superficial contact but also establishing a relationship between the student and the older patient (Adelman 2007: 1445; Allan \& Johnson 2009:1). Thanks to such a relationship, young people's understanding of the problems of old age improves and, as a result, stereotypes are broken, and a better image of old age is constructed (Taylor 2016).

Also in the case of older people who had to face difficulties and overcome many emotions such as fear, anxiety or nervousness while setting up a connection in order to contact the itCS, such education had a multifaceted dimension. First of all, attention should be paid to increasing the competences of older people in the use of smartphones (or computers) and applications such as instant messaging. On the screens, students and academic teachers many times saw the smiling faces of older adults suddenly appearing, often accompanied by loudly spoken words of joy at the meeting. Older adults, accustomed to phone calls, particularly emphasised the value of a conversation conducted not only with the use of sound, but also moving image, and described this form of contact as a more satisfying one. Moreover, when the connection worked, and the patient was able to deal with the (initially) complicated equipment, they felt a sense of satisfaction and driving force. Such experience teaches the older person that it is worth making an effort, even if the task seems at first difficult or impossible to accomplish.

Older adults' ability to establish a connection and use social messaging reduces their level of digital exclusion. It is estimated that digital exclusion concerns about $30-40 \%$ of older adults in Poland, so itCS, by educating older adults who are able to share the attained skills, counteracts the phenomenon of digital exclusion. Indeed, as demonstrated, the majority of older people confirm that contact with younger people helped them acquire new skills, such as computer or internet use. Usefulness is considered to be one of the key elements of technology acceptance (Morris et al. 2003: 425). Moreover, it was also shown that the perception of the social presence 
with the use of technologies impacted the degree of perceived usefulness positively, trust and intrusiveness, which was confirmed in practice by our project (Etemad-Sajadi \& Gomes Dos Santos 2019:713).

COVID-19, unfortunately, put the issue of digital poverty of older adults in the spotlight. It was known before that this age group had less access to the Internet than their younger counterparts. According to the Digital Economy Outlook Report from the Organization for Economic Cooperation and Development (OECD), in 2017, 96.5\% of those who were 16-24-year-olds were connected to the Internet and only 62.8\% of 55-74-year-olds (OECD 2017). Furthermore, it was shown that even if older adults do use the Internet, they are likely do so at a more basic level than younger age groups (Van Boekel et al. 2017: e180). As far as access to telemedicine services is concerned, besides a WiFi connection, video-enabled devices and digital literacy are essential. The study of Utley and colleagues (Utley et al. 2021:1) demonstrated that once older adults were equipped with visual communication devices, only one person in three was able to establish a connection successfully, which shows that technological literacy is a critical issue. Our project, thanks to the activities undertaken by the students, resulted in substantial lowering of this barrier.

For older adults consulted by the itCS, contact with students filled the gap that arose during the lockdown period, when there was a strong recommendation for older people regarding the need to isolate themselves, and not to contact even their loved ones. One of the older adults, talking about how she felt during the pandemic, when she could at long last have contact with students, said: "someone will call, and there is this contact at the moment when there is no direct contact". Social interactions are arguably strongly linked to positive affect, longevity, and good health. While older subjects are known to be at high risk of many dangers related to COVID-19, social distancing and isolation present challenges for their mental health. It is thus imperative to take into account this kind of toll taken on vulnerable older persons while fighting the pandemic (Older Adults, Social Isolation, and Technology During COVID-19 Pandemic 2020). Moreover, loneliness and social isolation are known risk factors for chronic diseases and vice versa, creating a vicious cycle and, additionally, the treatment of socially isolated older adults comes at a substantial annual cost. If they are ordered to stay at home and have their shopping delivered, and consequently avoid social contacts, actions must be taken to compensate for the consequences of social isolation for their physical and mental health.

As demonstrated by the meta-analysis of Wrzus and colleagues found that when the family network was stable in size from adolescence to old age, both the personal network and the friendship network decreased over time (Wrzus et al. 2013:53). Contrariwise, the pandemic affected all social contacts equally, as it introduced the fear that relatives could be infected during the visits, hence even the grandchildren were requested not to visit their grandparents. Henceforth, the itCS was a welcome response to the existing 
situation, as it filled the unmet needs that were present and gave the opportunity to establish contact with another person at a time when any meetings were de-recommended:

I hear that many people suffer from this situation [the epidemic], that their psyche fails. I met these [young] people [students] for the first time, but my tolerance is high, and I recognise that as young people they can behave well and that they are willing to help.

In this statement, the older adult appreciates the possibility of contact with another person, even if it is only a remote one, but at the same time presents his positive attitude towards young people. Such a good attitude of older adults to young people was also shown in the study conducted by Cybulski and colleagues, which showed that as many as $85 \%$ of the older persons surveyed gave a positive answer to the question whether they like the contact with young people, even if these contacts are rare and limited to meetings a few times a year (Cybulski et al. 2013:1099). According to this study, almost half of the surveyed older participants of the University of the Third Age believed that it was necessary to integrate older adults and young people to achieve mutual profits. Among the benefits that older adults may derive from contacts with young people, the greater chance of older adults being more active in many areas of life is emphasised.

The profits of remote contact between an older adult and a student within itCS are thus multidirectional, with not only an individual dimension but also a social one. These effects, although observed particularly "here and now" during the pandemic, are also long-term in nature and apply to both the younger and the older generation. In summary, it is worth quoting the words of one of the older adults consulted by the itCS, who said: "due to the COVID-19 epidemic, the world has changed and the itCS has become a mainstay, a hope [...]."

\section{For further discussion...}

The initiative was created in response to the needs of older adults resulting from the measures introduced during the lockdown and out of concern for older persons. Thanks to itCS, they obtained professional and reliable medical advice on an ongoing basis while reducing exposure to the novel coronavirus. The aim of the activities undertaken was the consultation of older people by means of remote communication, such as instant messaging or telephone. Satisfied patients are the best showpieces of itCS. In conclusion:

- Our project shows the effectiveness of the learning of cooperation between students of various medical specialties in solving problems of older people. 
- A notable innovation of our project is the unique intergenerational lesson. Both students and older subjects learned how to communicate and understand each other and overcome technological barriers.

- We are working on a solution that will allow us to transfer the itCS experience to the post-pandemic times.

\section{References}

Adelman, R.D., Capello, C.F., LoFaso, V., Greene, M.G., Konopasek, L., Marzuk, P.M. Introduction to the older patient: A "first exposure" to geriatrics for medical students. JAGS 2007, 55(9): p. 144-1450

Allan, L.J., Johnson, J.A. Undergraduate attitudes toward the elderly: The role of knowledge, contact and aging anxiety. Educ Gerontol 2009, 35(1): p. 1-14

Birkenmaier, J., Rowan, N.L., Damron-Rodriguez, J., Lawrance, F.P., Volland, P.J. Social work knowledge of facts on aging: Influence of field and classroom education. Educ Gerontol 2009, 35(9): p. 784-800

Cottle, N.R., Glover, R.J. Combating ageism: Change in student knowledge and attitudes regarding aging. Educational Gerontol 2007, 33(6): p. 501-512

Cybulski, M., Krajewska-Kułak, E., Sowa, P., et al. Elderly peoples' perception of young people: A preliminary study. Iran J Public Health 2013; 42(10): p. 1105

Delle Fave, A., Bassi, M., Boccaletti, E.S., Roncaglione, C., Bernardelli, G., Mari, D. Promoting well-being in old age: The psychological benefits of two training programs of adapted physical activity. Front Psychol 2018; 9: p. 828

Etemad-Sajadi, R., Gomes Dos Santos, G. Senior citizens' acceptance of connected health technologies in their homes. Int J Health Care Qual Assur 2019; 32(8): p. 1162-1174

Ferguson, A. Wanted: Gerontological social workers-factors related to interest in the field. Educ Gerontol 2012, 38(10): p. 713-728

Gémes, K., Talbäck, M., Modig, K., et al. Burden and prevalence of prognostic factors for severe COVID-19 in Sweden. Eur J Epidemiol 2020; 35(5): p. 401-409

Hägg, S., Jylhävä, J., Wang, Y., et al. Age, frailty and comorbidity as prognostic factors for short-term outcomes in patients with COVID-19 ingeriatric care. JAMDA 2020, DOI: https://doi.org/10.1016/j.jamda.2020.08.014

Langhammer, B., Bergland, A., Rydwik, E. The importance of physical activity exercise among older people. Biomed Res Int 2018; 2018: p. 7856823

Morris, M.G., Hall, M., Davis, G.B., Davis, F.D., Walton, S.M. User acceptance of information technology: Toward unified view. MIS Q 2003, 27(3): p. 425-478

Neumann-Podczaska, A., Al-Saad, S.R., Karbowski, L.M. et al. COVID 19-clinical picture in the elderly population: A qualitative systematic review. Aging Dis 2020; 11(4): p. 988-1008

OECD Secretariat OECD Digital Economy Outlook 2017. Organisation for Economic Cooperation and Development (OECD) 2017; https://www.oecd.org/digital/oecd-digital-economy-outlook-2017-9789264276284-en.htm

Older Adults, Social Isolation, and Technology During COVID-19 Pandemic. https://www.thectac.org/2020/05/older-adults-social-isolation-and-technologyduring-covid-19-pandemic/B-TACT he Blog to Transform Advanced Care. Advancing Care through Innovation, Observation and Collaboration

Peek, S.T.M., Luijkx, K.G., Vrijhoef, H.J.M., et al. Understanding changes and stability in the long-term use of technologies by seniors who are ageing in place: $A$ dynamical framework. BMC Geriatr 2019; 19(1): p. 236 


\section{Stawomir Tobis et al.}

Pinkas, J., Jankowski, M., Szumowski, Ł., et al. Public health interventions to mitigate early spread of SARS-CoV-2 in Poland. Med Sci Monit.2020; 26: p. e924730

Taylor, N.A., Ageism: Abilene Christian University Students' perception of aging adults. Digital Commons@ACU, Electronic Theses and Dissertations 2016. Paper 24

The American Geriatrics Society expert panel on person-centered care: A definition and essential elements. JAGS 2016, 64(1): p. 15-18

Utley, L.M., Manchala, G.S., Phillips, M.J., Doshi, C.P., Szatalowicz, V.L., Boozer, J.R. Bridging the telemedicine gap among seniors during the COVID-19 pandemic. J Patient Exp 2021; 8: p. 1-4

Van Boekel, L.C., Peek, S.T., Luijkx, K.G. Diversity in older adults' use of the internet: Identifying subgroups through latent class analysis. J Med Int Res 2017, 19(5): p. e180

Wieczorowska-Tobis, K. What does it mean "to be old"? In: Musielak, M. (ed.), Many facies of being old. Health and socio-cultural aspects of aging. Poznan University of Medical Sciences 2006, p. 11-16

Wrona, M., Tobis, S., Wieczorowska-Tobis, K., Neumann-Podczaska, A. COVID-19: Prevention and future initiative within nursing homes. JMS [Internet] 2020, 89(3): p. e451

Wrzus, C., Hänel, M., Wagner, J., Neyer, F.J. Social network changes and life events across the life span: A meta-analysis. Psychol Bull 2013, 139: p. 53-80 